\title{
Assessment of stress, coping and presenteeism in a nephrology unit
}

\author{
Juliane Umann ${ }^{1}$, Rodrigo M Silva ${ }^{2}$, Laura A Guido² \\ 1. Universidade Federal do Rio Grande do Sul, São Gabriel, Rio Grande do Sul, Brazil. 2. Universidade Federal de Santa \\ Maria, Santa Maria, Rio Grande do Sul, Brazil. \\ Correspondence: Laura A Guido. Address: 1000 Roraima Av. Camobi Road, Km 09, Floor 1302 - Builting 26, Santa Maria, \\ Rio Grande do Sul, Brazil. Email: Iguido344@gmail.com
}

Received: February 19, 2014

Accepted: May 23, 2014

Online Published: June 12, 2014

DOI : $10.5430 /$ jnep.v4n7p165

URL: http://dx.doi.org/10.5430/jnep.v4n7p165

\begin{abstract}
Background/Objective: Several investigations about stress, coping e presenteeism among nurses from different work units were already conducted in national and international context. However, few studies analyze these subjects in nurses who attend in nephrology units, where features and work process are specific to this unit. This study aimed to assess stress, coping and presenteeism among nurses attending in a nephrology service.
\end{abstract}

Methods: It is a quantitative, descriptive and cross-sectional research conducted in a nephrological unit from a teaching hospital between March and April 2010. The population was composed by three nurses on direct assistance to patients admitted in the nephrological award. We applied a form to sociodemographic characterization, the Occupational Stress Inventory, Occupational Coping Scale and the Work Limitations Questionnaire. The variables were statistically analyzed through the Statistical Package for the Social Sciences (SPSS - version 17.0). Qualitative variables were described through absolute and relative frequencies and qualitative ones through median, interquartile range, average and standard deviation.

Results: Results indicated high stress intensity in this population, and nurses assessed the interpersonal relationships as the highest stressful situation. The coping strategy most used for nurses of nephrology unit was Symptoms handing. Regarding to presenteeism analysis, we obtained a productivity loss rate of $5.5 \%$, with emphasis on physical and mental-interpersonal requirements.

Conclusions: We concluded that nurses assessed the situations from work environment as stressful and they use coping strategies focused on emotion, which are considered non effective to deal with stress. It may explain the high stress intensity found among nurses, which is a possible reason for the productivity loss.

\section{Key words}

Stress, Psychological, Adaptation, Psychological, Nephrology

\section{I ntroduction}

The work-related health risks depend on the kind of professional activity and on the conditions where the job is performed. In this sense, health services, specially the hospitals, many times provide unhealthy work conditions to workers ${ }^{[1]}$. Among 
these professionals, we stand out the nurses, who are exposed to factors which impact on their health and well-being, such as overwork and shift work ${ }^{[2]}$.

The shift work, typical of the nursing profession, is featured by uninterrupted care and the job is performed in periods commonly used by another profession's workers to resting, leisure, social, and family activities ${ }^{[1]}$. Also, nurses experience the overwork, defined as the considerable number of tasks which have to be done in a specific range of time or the excessive requirements linked to nurses' job ${ }^{[1]}$. In a research conducted among nurses and nursing staff attending in a teaching hospital, the workload mean was 52\%, what correspond to 12.5 hours of care provided per patient in 24 hours, indicating the presence of overwork ${ }^{[3]}$.

During nursing care in nephrology units, nurse experiences the chronicle illness, remains long time close to patients and to their relatives, and needs to specific scientific knowledge to attend in nephrology field ${ }^{[4]}$. Moreover, these professionals intervene directly through guidelines about the kidney disease and its progression, the treatment modalities, the daily activities and the adjustments in order to avoid a poor adherence to treatment ${ }^{[3]}$. Also, an adequate number of professionals to achieve the requirements from unit is needed, what not always occurs, causing overwork and impacting on nursing care quality in nephrology ${ }^{[3]}$. Thus, nurses may assess some situations as stressors and, then, experience the occupational stress. This phenomenon occurs when the work demand exceeds the worker's coping abilities and, this way, it stem from the interaction between work conditions and professional characteristics ${ }^{[5,6]}$. In this sense, investigations, using different psychometric instruments, found high stress levels in hospital nurses ${ }^{[6-8]}$. Also, researchers highlighted that the interpersonal relationships, the activities linked to personal management and the factors intrinsic to the work are the most reported stressors among nurses ${ }^{[6-9]}$.

In order to relieve the occupational stress, individuals need to apply coping strategies to hand with the perceived stressors from work environment is needed. These strategies are defined as any individual attempt for adaption to unpleasant circumstances, which are perceived as stressful, independently of the success or otherwise of their use ${ }^{[10]}$. They may be problem-focused, when the mainly worry is the solving the problem, or emotion-focused, when the strategies stem from defensives attitudes, leading the individual to avoid a showdown with the threat without changing the situation ${ }^{[11,12]}$. Concerning this, researches performed with nurses from specialized units indicate the problem-focused strategies as the most used by nurses to handle with work environment's stressors ${ }^{[6,8,9,13]}$. However, in the chronic kidney diseases situations, there is not a cure and, thus, the physical and psychological suffering of patients remains during the internship even with the treatment and medicines. So, the use of problem-focused strategies, considered the more effective to lead to stressors from occupational context, may be not useful or effectives, causing a higher level of stress in nurses of nephrology units and impacting on their health, on productivity and on nursing care quality. This linkage between medical conditions, including stress, and productivity loss is inserted in the concept of presenteeism, described as a condition in which people attend to work environment, but the tasks included in workers' role are performed of a nonproductive way, i.e., there is not a good performance due to physical and mental illness related to work process ${ }^{[14]}$.

The presenteeism occurs due to overwork and to insecurity feelings, situations that come from the new relationships established in the work environment. These relationships are characterized for increasing of unemployment rates, restructuring of public and private sectors, decreasing of organization size, reducing of workers number, numeric increasing of people on temporary contracts and reducing of benefits to workers ${ }^{[15]}$. About this, researchers found that carrying health treatment, duration of employment, and occurrence and number of work absences were variables significantly associated to presenteeism among hospital nurses ${ }^{[15,16]}$. When the diseases related to presenteeism were analyzed among 296 hospital nurses from Portugal, the researchers observed that lumbar pain, respiratory infections, migraine and stress were the main causes of presenteeism ${ }^{[16]}$.

Based on the foregoing, we verified that several investigations about stress, coping e presenteeism among nurses from different work units were conducted in national and international context ${ }^{[6-9,16,17]}$. However, few studies analyze these 
subjects in nurses who attend in nephrology units, where features and work process are specific to this unit. Thus, this study aimed to assess stress, coping and presenteeism among nurses attending in a nephrology service.

\section{Methods}

It is a quantitative, descriptive and cross-sectional research. This investigation is a part of a master dissertation, conducted with 129 nurses, being that three of these professionals attend in nephrology unit of a teaching hospital in Rio Grande do Sul, Brazil. We included nurses of the permanent staff who work in direct assistance to patients. We excluded those nurses who were in leave by any reason.

Data collection was conducted between March and April 2010 through a research protocol, which included: a form to sociodemographic and occupational characterization, the Inventory of Stress in Nurses (ISN), the Occupational Coping Scale (OCS) and the Work Limitations Questionarie (WLQ). These instruments were given to the subjects who accepted to participate in the research and its filling happened outside the working environment.

The ISN, developed and validated for the Brazilian population by Stacciarini e Tróccoli ${ }^{[5]}$, is composed of 38 items concerning the stressors from work environment. These stressors are assessed through a likert-type scale of 5 points in which: one is marked for 'never', two 'rarely', three 'sometimes', four 'many times', five 'always'. The instrument is made up of three categories for the work environment stressors, as follows: Interpersonal Relations, Stressors Roles of the Career and Factors Intrinsic to the Work ${ }^{[5]}$.

The Interpersonal Relations category contains 17 items (2, 3, 11, 13, 19, 20, 21, 22, 23, 24, 25, 27, 28, 33, 35, 37, 38) which approach the relationships established by nurse with other professional, patients and their relatives, students, work team and his/her own family into the work environment. The Stressors Roles of the Career contains 11 items (15, 16, 17, $18,26,29,30,31,32,34,36$ ) and refers to questions such as lack of recognition, autonomy, and the indefiniteness of the profession, impotence facing the situations, aspects of the physical environment and institutional organization (see Table 1). The Factors Intrinsic to the Work, third category of the inventory, is composed by 10 items $(1,4,5,6,7,8,9,10,12,14)$ which deal with the working functions performed, such as working hours and inadequate resources ${ }^{[5]}$. The ISN allows measuring the general occupational stress of the nurse based on the averages of scale's items. The assessment of categories is performed through the average of items that compose each ISN's category. Thus way, the index of general stress and per category may present values ranging from one to five, which respectively correspond to the lowest and to the highest scores in the stress scale.

The WLQ was translated, culturally adapted and validated for the Brazilian reality in order to assess presenteeism ${ }^{[18]}$. This assessment is obtained based on the lost productivity measure, associated with the interference of health problems in work activity performance. The instrument comprises 25 items, grouped in four work limitation domains which approach the multidimensional character of functions performed in the work environment, as follows: Time Management comprises five items which approach the difficulties to meet schedules and tasks within the time allotted; Physical Demand is composed by six items which assess the ability to perform tasks that require bodily strength, resistance, movement, coordination and flexibility; Mental-interpersonal Demand contains nine items which evaluate the difficulty to perform cognitive work tasks and to interact with people in work; Output Demand, with five items (questão 5) which refer to decrements in the ability to achieve the necessary quantity and quality of finished work in due time. For the analysis of this instrument, each item was scored as follows: no part of time (one point), a small part of time (two points), some part of time (three points), most of the time (four points) and the whole time (five points). WLQ domain scores range from zero (no limitation) to 100 (full-time limitation), indicating the percentage of time the individual was limited to perform activities at work in last two weeks ${ }^{[18]}$. 
Table 1. Description of items according to each ISN's category. Santa Maria, 2013.

\begin{tabular}{|c|c|c|}
\hline \multicolumn{3}{|l|}{ Instrument's Categories } \\
\hline Factors Intrinsic to the Work & Interpersonal Relations & Stressors Roles of the Career \\
\hline $\begin{array}{l}\text { 01- } \\
\text { 04- Doing a repetitive task. } \\
\text { 05- Felling emotional stress to the work. } \\
\text { 06- Making physical effort to achieve the } \\
\text { goals at work } \\
\text { 07- Developing activities beyond my } \\
\text { occupational role. } \\
\text { 08- Respond to more than one role at } \\
\text { work. } \\
\text { 09- Performing in real a larger work time. } \\
\text { 10- Taking tasks to do at home. } \\
\text { 12- Conciliating the professional } \\
\text { situations with the personal ones. } \\
\text { 14- Keeping updated. }\end{array}$ & $\begin{array}{l}\text { 02- Performing different tasks simultaneously. } \\
\text { 03- Solving unintended situations that happen } \\
\text { in work environment. } \\
\text { 11-Managing or supervising the work of other } \\
\text { people. } \\
\text { 13- Lack of materials needed for working. } \\
\text { 19- Doing alternated work shifts. } \\
\text { 20- } \\
\text { 21-Working in an unhealthy environment. } \\
\text { 22- Working at night. } \\
\text { 23- Relationship with nurses of work } \\
\text { environment. } \\
\text { 24- Relationship with medical team. } \\
\text { 25- Relationship to the leading } \\
\text { 27- Providing assistance to the patient. } \\
\text { 28- Providing assistance to critical patients. } \\
\text { 33- Performing fast procedures. } \\
\text { 35- Restriction of the professional autonomy. } \\
\text { 37- Feeling impotent face the tasks that have } \\
\text { to be done. } \\
\text { 38- Exclusive dedication to the profession. }\end{array}$ & $\begin{array}{l}\text { 15-Lack of human resources. } \\
\text { 16- Working with unprepared } \\
\text { people. } \\
\text { 17. Working in an inadequate } \\
\text { physical installations. } \\
\text { 18. Lack of time in work to argue } \\
\text { about the negative and positive } \\
\text { experiences. } \\
\text { 26- Working in team. } \\
\text { 29- Attending to the patients' } \\
\text { relatives. } \\
\text { 30- Detachment between theory and } \\
\text { practice. } \\
\text { 31- Teaching the student. } \\
\text { 32. Developing researches. } \\
\text { 34. Having a short deadline to get } \\
\text { orders. } \\
\text { 36. Influence of work institutional } \\
\text { politics. }\end{array}$ \\
\hline
\end{tabular}

Table 2. Description of items according to each OCS factor. Santa Maria, 2013.

\begin{tabular}{|c|c|c|}
\hline \\
\hline Control & Avoidance & Management of Symptoms \\
\hline $\begin{array}{l}\text { 01. I talk to my workmates who are also } \\
\text { involved in the problem. } \\
\text { 02. I try to see the situation as na opportunity } \\
\text { to learn and to develop new abilities. } \\
\text { 03. I spend extra attention to the problem. } \\
\text { 04. I think to myself as someone who always } \\
\text { goes well in situations like this. } \\
\text { 05. I think in the situations as a challenge. } \\
\text { 06. I try to work in the fastest and most } \\
\text { efficient way. } \\
\text { 07. I decide about what should be done and I } \\
\text { communicate to other people involved. } \\
\text { 08. I struggle to do what I think is expected } \\
\text { from me. } \\
\text { 09. I ask for advices of people who, although } \\
\text { are out of the situation, may help me to } \\
\text { decide what to do. } \\
\text { 10. I try to change the factors that caused the } \\
\text { situation. } \\
\text { 11. I get involved more in my tasks if I } \\
\text { believe that it can help me to solve the issue. }\end{array}$ & $\begin{array}{l}\text { 12. I avoid the situation if it is } \\
\text { possible. } \\
\text { 13. I say to myself that the time } \\
\text { solve the problems of this nature. } \\
\text { 14. I try to keep distance from the } \\
\text { situation. } \\
\text { 15. I try to remember that work is } \\
\text { not everything in life. } \\
\text { 16. I anticipate the negative } \\
\text { outcomes, preparing myself to the } \\
\text { worst. } \\
\text { 17. I delegate my tasks to other } \\
\text { people. } \\
\text { 18. I keep the most possible } \\
\text { distance of people who caused me } \\
\text { the situation. } \\
\text { 19. I try do not worry about the } \\
\text { situation. } \\
\text { 20. I keep me focused in doing } \\
\text { primarily those things I like. }\end{array}$ & $\begin{array}{l}\text { 21- I do more physical exercises. } \\
\text { 22- I use some kind of relaxing strategy. } \\
\text { 23- I look for the company of another people. } \\
\text { 24- I change my intake habits } \\
\text { 25- I try to participate of more leisure } \\
\text { activities. } \\
\text { 26- I buy something. } \\
\text { 27- I take a couple days for resting. } \\
\text { 28- I do a trip. } \\
\text { 29- I become more dreamer. }\end{array}$ \\
\hline
\end{tabular}

After data collection, variables were statistically analyzed by mean of Statistical Package for the Social Sciences (SPSSversion 17.0) software. The qualitative variables were described through absolute and relative frequencies and the 
quantitative variables through averages and standard deviation (sd). The instruments' reliability was evaluated through the Cronbach's Alpha coefficient.

In order to meet the Brazilian National Health Council's guidelines and standards as established for studies involving human subjects (Resolution CNS 196/96), the data collection was performed after the institutional ethical council approved the project of this research (protocol $\left.n^{\circ} 0312.0 .243 .000-09\right)^{[19]}$. Also, the invited participants who voluntarily consented to participate in the study received the free and informed consent form.

\section{Results}

In the evaluation of the instruments' internal consistency, we found that Cronbach's Alphas ranged between 0.789 and 0.954, what attest the satisfactory reliability of the instruments (Values obtained from the primary research, linked to the dissertation named Stress, Coping and presenteeism in Hospital Nurses due to the impossibility of applying this test for the population analyzed in this paper.).

The sociodemographic and occupational characteristics highlighted that all nurses are female, post-graduated, without work absences, performing extra hours in work and under health treatment during the data collection. We observe that the most professionals of the nephrology unit, (two of three nurses), are married, work without a shift defined, perform a training to work in the referred unit and have not another job. Also, we verify that nurses, on average, are 36 years old (sd $=4.00)$, have one son/daughter(sd = 1.00), attend for 7,41 years $(\mathrm{sd}=0.68)$ in the health institution and for 4,83 years in the unit (sd $=3.91)$, as well as they experience a weekly workload of 38,66 hours ( $\mathrm{sd}=2.30$ ).

The results of stress assessment indicate high stress intensity once the general average of the ISN was 3.48(sd $=0.72$ ). Among the most stressful situations, those related to Interpersonal Relations are predominant. Thus, nephrology nurses assess the relations with other professionals, patients and their relatives, students, work team and his/her own family as the most stressful into the work environment (see Table 3).

Table 3. Descriptive measures for the ISN/Categories and for the OCS/Factors. Santa Maria, 2011.

\begin{tabular}{lll}
\hline ISN/Categories & Average & Standard-Deviation \\
\hline Interpersonal Relations & 3.51 & 0.78 \\
Factors Intrinsic to the Work & 3.47 & 0.67 \\
Stressors Roles of the Career & 3.45 & 0.73 \\
OCS/ Factors & & \\
Management of Symptoms & 3.44 & 0.59 \\
Control & 2.79 & 0.59 \\
Avoidance & 2.63 & 0.32 \\
\hline
\end{tabular}

Considering the averages for each item of the ISN, we present those of highest and lowest averages, i.e., the situations/ conditions of the occupational environment which represent the highest and the lowest stress for nurses in daily work of the nephrology unit. In this sense, we verify that the item 6 "developing activities beyond my occupational role" is the most reported $(X=4.33$; $s d=0.57)$. The item 19 "Relation with nurses of the health team" presented the lowest score in the ISN assessment $(X=2.33$; sd $=1.15)$.

Descriptive measures for the factors of the Occupational Coping Scale are presented on Table 1. In the analysis of OCS's factors, those which present higher scores signal the actions more used for nurses to manage manage the stressors stem from work environment. Thus, items with higher scores are: "I talk with my workmates who are experiencing the same problem" (item 1); "I strive to do what I think is expected from me" (item 8); "I anticipate the negative consequences, thus, preparing me for the worst” (item 16), with averages of 3.33 and 3.66 respectively (sd $=1.15$ ).

Published by Sciedu Press 
Concerning to Presenteeism, which is evaluated through the productivity loss, the WLQ index was $5.5 \%$ among the nurses attending in the nephrology unit. This result represents the percentage of decrease in the productivity of these nurses when compared to individuals completely healthy. In Figure 1, we show the loss productivity according to each domain of the WLQ.

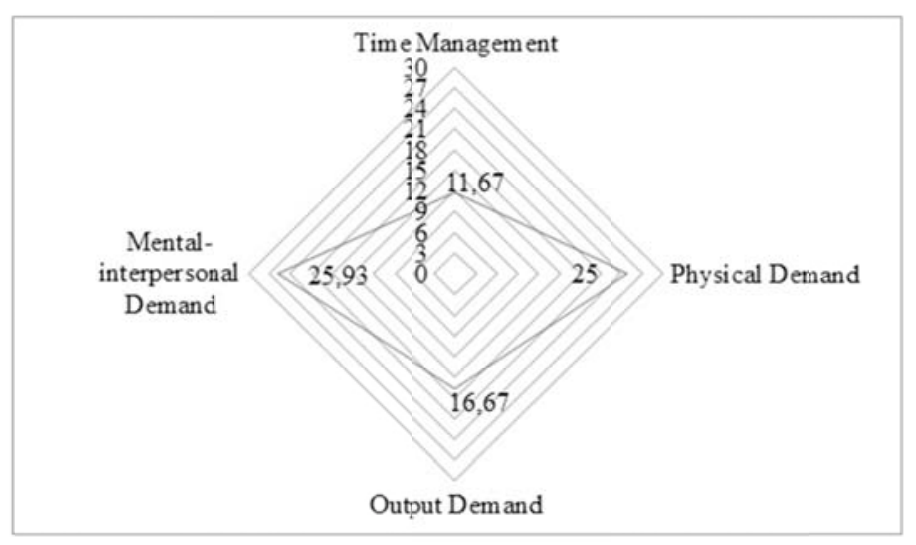

Figure 1. Lost productivity according to WLQ’s domains among nephrology unit nurses

As shown in Figure 1, the data indicate that, in the last two weeks, nurses have a limitation about $25 \%$ of their time to perform cognitive tasks in work, including those that require interactions with other people (Mental-Interpersonal Demand), as well as in those tasks that demand bodily strength, resistance, movement, coordination and flexibility (Physical Demand).

Based on the Likert scale of the WLQ, we found that the Physical Demand represented productivity loss "whole-time" for 66.6\% of answerers. The Output Demand, which is the work limitation domain, interferes "Most of the time" in the productivity according to $53.3 \%$ of nurses working in the nephrology unit (see Figure 2).

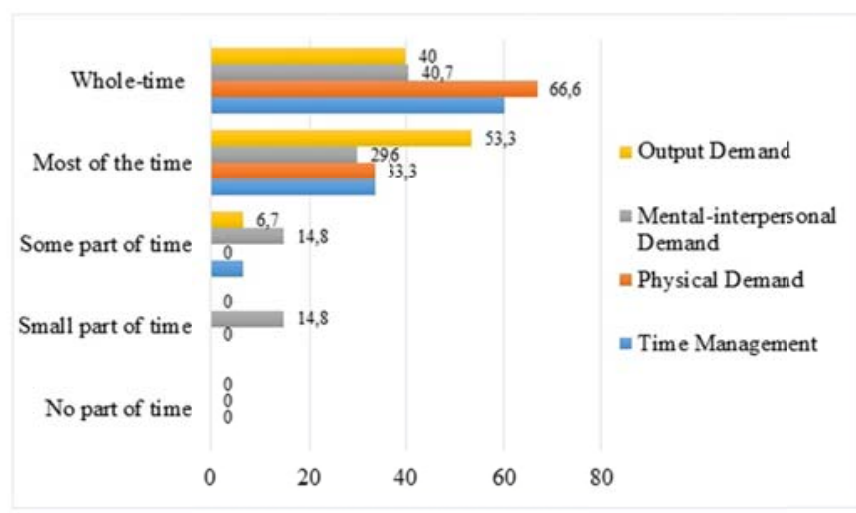

Figure 2. Distribution of WLQ/domains according to answer frequencies. Santa Maria. 2011.

We highlight that "No part of time" did not obtain enough percentages of answers to productivity evaluation in this population.

\section{Discussion}

Nurses of the nephrology service presented high stress intensity, being that the situations related to Interpersonal Relations represented the highest stress for these professionals. On other hand, in a study that evaluated stress among nurses with workload exceeding 30 hours a week, the authors found that professionals who work in the closed sector, including the 
hemodialysis, had lower scores of general stress and minimum score in the Interpersonal Relations ${ }^{[1]}$. These results were based on the assertive that the work in health field requires cooperative acting, creative perception, positive view of conflicts in order to nurses can manage the inter-relationships in a competent and synchronized way in the seek for common aims. All these skills may have become the stressors assessment easier for the professionals of this investigation.

However, the same authors verified higher scores of stress for the variables Personnel Management and Conflict of Roles ${ }^{[1]}$, what is in line with the results of this research concerning the task most reported as stressful: "Developing activities beyond my occupational role". The different roles, the lack of control and the absence of support from leadings to perform the job have been indicated as work features that influence on the stress occurrence and/or reduce the well-being of workers ${ }^{[15]}$.

We believe that the high scores of stress may be linked to the profile of patients in care in the nephrology unit of this investigation. A research demonstrated that patients admitted in a nephrology unit require semi-intensive care ${ }^{[3]}$. This found shows that the profile of patients involves a complexity higher than those expected in a care unit and requires that the nurse reevaluate and readjust the human, materials and technological resources to ensure a safe nursing care, directing the nursing work process to achieve the main demands of patient admitted in the nephrology unit ${ }^{[3]}$.

Thus, the trying of readjustment to work demands in a work context which has made the quantitative increases, related to human resources or to structural and materials, harder or impossible may negatively impact on the stressors assessment and, consequently, on the stress occurrence. About this situation, other research pointed that absent or insufficient control on the planning and execution of occupational activities is harmful to workers health, with repercussions to their self-esteem, and may lead to stress, to dissatisfaction and to strain in the work environment ${ }^{[2]}$.

There was predominance, in this study, of nurses using the factor Management of Symptoms, described as the use of strategies, including relaxing or physical activities, to deal with stressful situations. This kind of strategy is considered low effective to cope with the stressors, what may explain the presence of high stress intensity in nephrology nurses and surely evidence the difficulties found by nurses in occupational stress management.

Similarly, an investigation with Portuguese oncology nurses found a significant negative correlation between general health and emotion-focused strategies of coping ${ }^{[20]}$. This result strength the idea of strategies focused on individual avoidance work as protectors during one-off crises situations or when the resolution is impossible, but they do not promote physical and emotional balance in long-term situations, which demand the active participation of the individual ${ }^{[20]}$. Another investigation highlighted the prevalence of emotion- focused strategies among nurses working in anesthesia recovery room, what represents a defensive process regarding to the situations evaluated as stressful and probably suggest that the analyzed professionals were seeking for palliative outputs in the coping with stress at work ${ }^{[12]}$.

We stand out that the results of this paper are different of those found in other units which compose our research dataset, where there was prevalence of low and moderate stress levels and of the usage of problem-focused strategies, considered more resoluteness to cope with stressors. This is an essential finding because it evinces the specificity of work process as a mediator in the stress assessment and in the coping strategies selection.

In this context, we believe that the presence of patients in chronicle health condition and with reduced heal perspective work as important factors on the stress assessment and on the coping strategies selection by nurses of nephrology unit. Concerning this, researchers point the death, the frequent instability of clinical feature and the feeling of impotence face to disease, as well as the necessity of surveillance and technical- scientific improvement, as factors potentially stressful, which impact on the coping strategies choice ${ }^{[7,17]}$. Then, the referred situations might have influenced in the stress intensity and in the coping strategies choice (emotion-focused) of nephrology nurses. 
Concerning the presenteeism, evaluated through the productivity loss, we found an index of 5.5\%, what can be considered a reduced percentage for this population. An investigation, performed with 129 hospital nurses from Rio Grande do Sul (Brazil), identified a lost productivity of $4.84 \%$, evaluated as a reduced percentage too ${ }^{[14]}$. In this way, the productivity loss, even in low percentages, evidence that slightly consequences and interferences co-exist to services and institutions management, as well as to the nursing professionals and to the care provided ${ }^{[14]}$.

The adjustment between the ability to work and the requirements of the task which has to be done influence on the productivity and may be a cause of stress, malaise, illness and limitations linked to the nursing job ${ }^{[21]}$. On this perspective, we have to consider the multidimensionality related to productivity loss in the hospital context, as well as to emphasize the interaction between individual and environment and its influence on health.

The workers' perception about their environment, determined by cultural, social and individual aspects, can affect their physical and cognitive performance and, consequently, impact on their health status. This statement is supported by researchers who describe the personal features and the attitudes as causes of higher presenteeism occurrence and the factors related to the work as the main determinants on the decision to go to workplace even in cases of diagnosed phsicial or mental diseases ${ }^{[22]}$.

In this paper, the domain in which nurses presented the highest limitation score was Mental- Interpersonal Demand (25.93\%), followed by Physical Demand (25\%), Output Demand (16.67\%) and Time Management (11.67\%). In a research with Brazilian nurses, the domains Physical Demand and Mental- Interpersonal Demand were the main responsible for the lost productivity among these professionals ${ }^{[14]}$. Thus, the difficulties experienced by nurses to perform cognitive tasks at work and to interact with people were assessed as the limitation most influential to the lost productivity. Therefore, the peculiarities of nephrology unit care impact on the stress assessment and, consequently, on the nurses productivity.

The Physical Demand represented an important percentage of lost productivity for the nursing work. This feature has been analyzed under the view of ergonomics and involves the consequences and implications of physical efforts spent to perform work activities for the professional health. In a Brazilian research, the high work requirements were evaluated as predictors of pain, as well as of higher incidence of musculoskeletal disorders and repetitive strain injuries ${ }^{[2]}$. In an investigation conducted with 296 Portuguese nurses, including those working in nephrology units, musculoskeletal (46.1\%) and respiratory (41.4\%) diseases were the main disorders related to the presenteeism ${ }^{[16]}$.

In this sense, it is already known that the health services, in particular the hospitals, provide worse work conditions for their workers than other work sectors. Therefore, we have to consider the lack of resources as a intervene factor to achieve the required productivity in the workplace. This supposition was confirmed by studious who proved that insufficient resources increase the number of presenteeism cases and the levels of musculoskeletal pain, working, therefore, as predictors of presenteeism and of increased probability of chronicle diseases ${ }^{[22]}$. These studious refer that inadequate work conditions to perform the tasks at work environment is a double risk factor because it promotes the work insecurity and increases the risks of errors and accidents.

\section{Conclusion}

Nurses of nephrology assessed the situations from work environment as stressful and they use emotion-focused coping strategies, which are considered non effective to deal with stress. It may explain the high stress intensity found among nurses, which is a possible reason for the productivity loss. Based on the showed results, we confirm the repercussion of the peculiarities linked to the nephrology work environment on the stress perception, Coping choices and, consequently, on the productivity loss of nurses. 
As limitations, we highlight the number of individuals who composed the population of this study, what made some analyses and inferences harder. Concerning the WLQ, the different psychometric instruments and analysis techniques used for researchers interfered on the comparisons of the findings involving nurses, especially those from international studies. Besides, the conclusions are limited to the period when the population was investigated because we performed a cross-sectional and descriptive investigation. For the same reason, inferences concerning to the continuity of found situation and to long term relationships among stress, coping strategies and presenteeism are not possible.

This way, new studies involving nephrology nurses, a larger population and a longitudinal design should be conducted. So, it will be possible to know if stress intensity, coping strategies and presenteeism present a specific standard for nephrology nurses, once the work environment is featured for the chronicity and for the reduced perspective of heal.

As advances, we point the conjunct analysis of presenteeism, stress and coping strategies among nephrology nurses. It is an advance because the presenteeism is generally analyzed under the aegis of health and illness status of nursing professionals, but the assessment of environment by nurses and its repercussion on their diseases and lost productivity are not considered.

\section{References}

[1] Santos TMB, Frazão IS, Ferreira DMA. Workload-related stress in nurses in a university hospital. Cogitare Enferm. 2011; 16(1): 76-81. Available from: http://ojs.c3sl.ufpr.br/ojs/index.php/cogitare/article/viewFile/21115/13941

[2] Umann J. Guido LA, Freitas EO. Knowledge production about health-disease in a nursing team in hospital assistance. Ciênc cuid saúde. 2011; 10(1): 162-68. http://dx.doi.org/10.4025/cienccuidsaude.v10i1.10931

[3] Trepichio PB, Guirardello EB, Duran ECM, Brito AP. Patient profile and nursing workload at the nephrology unit. Rev Gaúcha Enferm. 2013; 34(2): 133-39. Available from: http://www.scielo.br/pdf/rgenf/v34n2/en_v34n2a17.pdf PMid:24015472 http://dx.doi.org/10.1590/S1983-14472013000200017

[4] Prestes FC, Beck CLC, Tavares JP, Silva RM, Cordenuzzi OCP, Burg G, et al. Nursing worker perceptions on hemodialysis service patients and labor dynamics. Texto \& Contexto Enferm. 2011; 20(1): 25-32. http://dx.doi.org/10.1590/S0104-07072011000100003

[5] Stacciarini JMR, Tróccoli BT. An instrument to measure occupational stress: a nurses' stress inventory Rev latinoam enferm. 2000; 8(6): 40-9. http://dx.doi.org/10.1590/S0104-11692000000600007

[6] Umann J, Silva RM, Benetti ERR, Guido LA. Stress and coping among nurses of hemato-oncologic units. Rev Rene. 2013; 14(4): 783-90. Available from: http://www.revistarene.ufc.br/revista/index.php/revista/article/viewFile/1212/pdf

[7] Lee WL, Tsai SH, Tsai CW, Lee CY. A study on work stress, stress coping strategies and health promoting lifestyle among district hospital nurses in Taiwan. J Occup Health. 2011; 53(5): 377-83. http://dx.doi.org/10.1539/joh.11-0054-FS

[8] Kleinubing RE, Goulart CT, Silva RM, Umann J, Guido LA. Stress and coping in nurses of adult and cardiological intensive care. Rev Enferm UFSM. 2013; 3(2): 335-44. Available from: http://cascavel.ufsm.br/revistas/ojs-2.2.2/index.php/reufsm/article/view/8924/pdf

[9] Guido LA, Umann J, Stekel LMC, Linch GFC, Silva RM, Lopes LFD. Stress, coping and health conditions of nurses in a medical clinic of a university hospital. Ciênc Cuid Saúde. 2009; 8(4): 615-21. http://dx.doi.org/10.4025/cienccuidsaude.v8i4.9690

[10] Pinheiro FA, Tróccoli BT, Tamayo MR. Coping measurement in occupational setting. Psicol Teor Pesq. 2003; 19(2): 153-8. http://dx.doi.org/10.1590/S0102-37722003000200007

[11] Lazarus RS, Folkman S. Stress, appraisal and coping. New York, Springer, 1984.

[12] Guido LA, Silva RM, Mari S. Coping estrategies among nurses in recovery room. Rev SOBECC. 2006; 11(3): 32-7.

[13] Guido LA, Silva RM, Goulart CT, Kleinübing RE, Umann J. Stress and coping among surgical unit nurses of a teaching hospital. Rev Rene. 2012; 13(2):428-36. Available from: http://www.revistarene.ufc.br/revista/index.php/revista/article/view/226/pdf

[14] Umann J, Guido LA, Grazziano ES. Presenteeism in hospital nurses. Rev latinoam enferm. 2012; 20(1): 159-66. http://dx.doi.org/10.1590/S0104-11692012000100021

[15] Laranjeira CA. An integrated perspective of the organisational context and experience of stress. Rev Salud Publica. 2009; 11(1): 123-33. http://dx.doi.org/10.1590/S0124-00642009000100013

[16] Martinez LF, Ferreira AI. Sick at work: presenteeism among nurses in a Portuguese public hospital. Stress Health. 2012 Oct; 28(4): 297-304. http://dx.doi.org/10.1002/smi.1432 
[17] Ashker VE, Penprase B, Salman A. Work-related emotional stressors and coping strategies that affect the well-being of nurses working in hemodialysis units. Nephrol nurs j. 2012; 39(3): 231-6. PMid:22866362

[18] Soárez PC, Kowalski CCG, Ferraz MB, Ciconelli RM. Translation into Brazilian Portuguese and validation of the Work Limitations Questionnaire. Rev panam salud pública. 2007; 22(1): 21-8. Available from: http://www.scielosp.org/pdf/rpsp/v22n1/a03v22n1.pdf PMid:17931484

[19] Health National Council(CNS). Resolution CNS n 196, October 10, 1996. It approves the guidelines and regulatory rules for research involving humans. Pesqui Odontol Bras. 2003; 17 (Supl 1): 33-41. Available from: http://www.sbpqo.org.br/suplementos/33\%20-\%20Diretrizes.pdf

[20] Gomes SFS, Santos MMMCC, Carolino ETMA. Psycho-social risks at work: stress and coping strategies in oncology nurses. Rev latinoam enferm. In press. http://dx.doi.org/10.1590/0104-1169.2742.2365

[21] Costa FM, Vieira MA, Sena RR. Disease-related absenteeism among nursing team members in a teaching hospital. Rev Bras Enferm. 2009; 62(1): 38-44. http://dx.doi.org/10.1590/S0034-71672009000100006

[22] Hansen CD, Andersen JH. Going ill to work - what personal circumstances, attitudes and work-related factors are associated whith sickness presenteeism? Soc sci med. 2008; 67(6): 956-64. http://dx.doi.org/10.1016/j.socscimed.2008.05.022 